\title{
Do Performance Assessment has Contribution to Achieve Students' Commnunication Skills?
}

\author{
Aisah Isnaeni ${ }^{1}$, A Ratna Wulan ${ }^{2}$ and R Solihat ${ }^{23}$ \\ ${ }^{1}$ Program Studi Pendidikan Biologi, Sekolah Pascasarjana Universitas Pendidikan Indonesia, Jl. \\ Dr. Setiabudi No. 229, Bandung 40154, Indonesia \\ ${ }^{2}$ Departemen Pendidikan Biologi, Universitas Pendidikan Indonesia, Jl. Dr. Setiabudi No. 229, \\ Bandung 40154, Indonesia \\ ${ }^{3}$ Corresponden Author \\ E-mail: isnaeniaisah@gmail.com
}

\begin{abstract}
Communication skill was an important component of education. This study aims to analyzed students' communication skills and response by using performance assessment on water cycle concept. The method that used in this study is descriptive. Subject consists of first-grade students' in senior high school (n:32). The instruments that used in this study are the task, observation sheets, questionnaire, self and peer assessment. Those instruments analyzed four indicators of communication such as; (1) articulate thoughts and ideas effectively,(2) listen effectively, (3) use communication for a range of purposes and (4) Communicate Effectively in diverse environments. Sccorring of instruments has two categories, score from 1-4 for task and sheets of observation, score from 0 and 1 for self and peer assessment and questionnaire using descriptive analyzed. Then, indicators of communication skills categorized into three groups: high, medium and low. The data showed that all of the indicators in medium categorized $81.3 \%$ in the first indicator, $53.1 \%$ in the second indicator, $46.9 \%$ in the third indicator, and $68.8 \%$ in the fourth indicator. Therefore students' have communication skill in medium category and most of the students' has positive respond in performance assessment because its' can help students' to fix their performance in the instructional process.
\end{abstract}

Keyword : Performance Assessment, $21^{\text {st }}$ Century Skills.

\section{Introduction}

In entering the $21^{\text {st }}$ century, education should prepare a student to posses skill needed to face the future. Some skills of the $21^{\text {st }}$ century which are important to be possessed by students are critical, creative and innovative thinking skill, collaborative skill and communication skill [1]. Communication skill becomes the focus of discussion in this article because communication skill has a very important role for someone to be able to adapt to their environment [2]. On the other side, humans as a social creature who interact with the others want their idea, expectation, and dream delivered through verbal or written can be understood by people who listen and read their writing. Depend on this, need communication process is emerged [3]. Due to this a very important role, the communication skill becomes one of the skills for 21 century. 
Based on the skills of the $21^{\text {st }}$ century, communication skill consists of four indicators namely (1) Articulate thoughts and ideas effectively using oral, written and nonverbal communication skills in and a variety of forms and context, (2) Listen effectively to decipher meaning, including knowledge, values, attitudes and intentions, (3) Use communication for a range of purposes (e.g. to inform, instruct, motivate and persuade) and (4) Communicate effectively in diverse environments (including multilingual).

Achieving the skills of the $21^{\text {st }}$ century is effected on the learning process, assessment and learning processing in class which is increasingly developed [4]. Therefore, there is need of assessment which can help students to train the skills of the $21^{\text {st }}$ century. Assessment for learning can train the skill because feedback given can help improvement during learning process [5]. Assessment for learning is one form of authentic assessment because the task assignment is real [6]. Frequently, the activity which demands students in performance is based on authentic task so performance assessment can assess the activity done by students during learning process [7].

\section{Method}

The method of study was descriptive. The subject of study involved were 32 students of first class in the senior high school located in Lembang. Each student was given the task in the form of project namely the making of water cycle diorama which was made in groups. During preparation, the making process and presentation of product result, each student was given the activity sheet as a reference to make that activity become directed. The process of communication assessment was done when students prepared the project and presentation of product which had been made. The assessment could be obtained by using the instrument in the form of observation sheet, self, and peer assessment. Assessment score for observation sheet in the form of a rubric which had score range 1 until 4 whereas for self-assessment score and peer assessment score were given the score 0 and 1 . The result of score obtained in each indicator of communication was made in percentage and then categorized into three groups namely high, medium and low.

Score of Communication Skill Indicator $(\%)=\frac{\text { the numbers of score obtained }}{\text { the number of total score }} \times 100 \%$

Table 2.1 Categorization

\begin{tabular}{ll}
\hline \multicolumn{1}{c}{ Percentage (\%) } & \multicolumn{1}{c}{ Categorization } \\
\hline Over 75 & High \\
$50-75$ & Medium \\
Under 50 & Low
\end{tabular}

To know the response of students to the use of performance assessment, students were given the response questionnaire during learning process which had been done. Students' response comprised task assignment and feedback which was done by the researcher. The answer consisted of four alternatives of answer namely, whole, most, few, and no. Students' response was analyzed qualitatively. 


\section{Result and Discussion}

\subsection{Students Communication Skill in Each Indicator}

Based on assessment which had been done, data was obtained in the form of percentage in each indicator of communication skill. The table below was the result of categorization percentage distribution in each indicator.

Table 3.1.1 Data of Communication Indicators Distribution

\begin{tabular}{lllllllll}
\hline No & \multicolumn{1}{c}{$\begin{array}{c}\text { Communication } \\
\text { Indicators }\end{array}$} & \multicolumn{3}{c}{ Category } & \multicolumn{3}{c}{ Percentage (\%) } & $\begin{array}{c}\text { Total } \\
(\mathbf{\%})\end{array}$ \\
\hline 1 & H & M & L & H & M & L & \\
\hline & $\begin{array}{l}\text { Articulate thoughts and } \\
\text { ideas Effectively }\end{array}$ & 3 & 26 & 3 & 9,4 & 81,2 & 9,4 & 100 \\
2 & $\begin{array}{l}\text { Listen Effectively } \\
3\end{array}$ & 15 & 17 & 0 & 46,9 & 53,1 & 0,0 & 100 \\
& $\begin{array}{l}\text { Use communication for a } \\
\text { range of purposes }\end{array}$ & 14 & 15 & 3 & 43,7 & 46,9 & 9,4 & 100 \\
4 & $\begin{array}{l}\text { Communicate Effectively } \\
\text { in diverse environments }\end{array}$ & 10 & 22 & 0 & 31,2 & 68,8 & 0,0 & 100 \\
\hline
\end{tabular}

Specification: H: High, M: Medium, L: Low

In the data above, it was obtained that $81.2 \%$ students were included in medium category in indicator of Articulate thought and ideas effectively which means that these students had made idea of water cycle diorama making then articulated it in the form of writing (in student worksheet which had been given), delivered that idea to their peers orally. However, the idea made was not suited to the concept which had been determined by the teacher. Most students delivered the idea theme of diorama making which was not suited with diorama concept that was three dimension miniature showing phenomena. One example the idea proposed which was not suited to diorama concept was made diorama by coloring drawing paper. The number of percentage of $9.4 \%$ students who were included in low category means that that student had made the idea and articulated that the idea in written or oral only. Based on researcher observation during the learning process, most students only articulated the idea effectively in writting. Whereas for $9.4 \%$ students who were included in the high category, it means that these students articulated the ideas which had been made in written then delivered it to their peers orally and the ideas delivered were suited with the determined concept.

The second indicator from communication skill using the word "listen" in this indicator showed a conscious process which needs mental attention of listening to something heard. Listen effectively was more than the cognitive process. A listener not only should understand something said verbally, but also nonverbal communication which informed the context listened [8]. In this indicator, there were no students who were included in the low category. In this category, students only capable to listen to 
the presentation of product making done by their peers by giving response without giving feedback. In indicator of $53.1 \%$, students were included in medium category, which means that students had been able to listen, gave response then feedback, but the feedback given was not suited to the topic of water cycle diorama and the product in which they gave feedback which was not suited to question about the way of presenter talked when explaining the product which had been made. Students who were included that high category were those who were able to listen effectively by giving response and feedback which was suited to the topic discussed. One example of feedback which was suited to students was students asked the question to presenter like this "why there is the difference in the color of cloud which is initially white color turned into grey color?" The cloud become dark is the sign that more water drops and ice crystal which cause the decrease of light intensity which passed through it so the lower part of cloud was seen grey as we saw. The percentage obtained for this category was $46.9 \%$.

In the indicator of use communication for a range of purposes, the aim was students capable of doing communication to give information about the topic to their peers in the group and communicated in the form of instruction. The instruction given could be the instruction for the material and equipment which should be taken by each individual. Making a product given encouragement and motivation to the student for improving their communication. Data on table 3.1 showed that $43.7 \%$ students had been able to communicate for only three purposes. Students who were included in low category mean that students used communication for only two purposes. Communicate orally could support well psychological development because one self-concept obtained from the interaction among the self with the others. So psychologically, the achievement in self- actualization involved communication activity such as give contribution in the group, influence the others and show the behavior which is socially accepted [9].

The forth indicator in communication skill was communicate effectively in diverse environments. In this article, the researcher limited the diverse environment only in the school environment in the form of product presentation in the classroom with product publication through media social (Line). In this indicator, there were no students included in the low category which mean that all students had been able to do product publication made in the form of presentation in the classroom. A total of $68.8 \%$ students was included in the medium category. It showed that students were able to do product publication which had been made by doing publication with the presentation in front of class and publication through media social but the caption was given were not suited to the topic discussed. The example of publication caption in social media which was not suited with the caption is saying thank to their peers for the product which had been made. A total of $31.2 \%$ students was included in the high category which means that they had been able to do product publication through class presentation and publication through media social accompanied by caption suited with the product made. 


\subsection{Communication Skill in Each Student}

Based on the gain of achievement in every indicators of communication skill possessed by students. It was found that there were four patterns. The gain of communication skill pattern in each student could be seen in the diagram below.

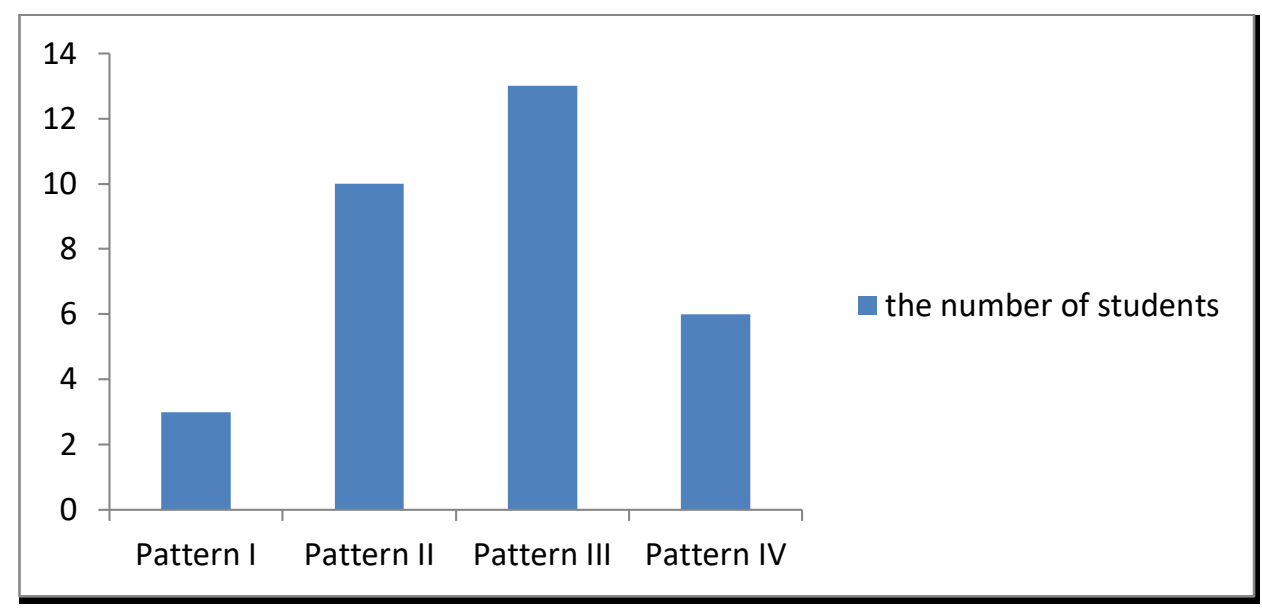

Figure 3.2.1 The Communication Skill Pattern

Tabel 3.2.1 Percentage of Communication Skill Pattern

\begin{tabular}{lll}
\hline No & \multicolumn{1}{c}{$\begin{array}{c}\text { The Communication } \\
\text { Skill Pattern }\end{array}$} & $\begin{array}{c}\text { Percentage } \\
(\%)\end{array}$ \\
\hline 1 & Pattern I & 9,4 \\
2 & Pattern II & 31,3 \\
3 & Pattern III & 40,6 \\
4 & Pattern IV & 18,7 \\
\hline
\end{tabular}

3.2.1 Pattern I. In this pattern, it was known that students had been able to fulfill three from four indicators of communication skill. This pattern was divided into two groups. In the first group, students did not fulfill indicator of articulate thought and ideas effectively. Whereas, in the second group, students did not fulfill indicator of Listen effectively. Both in the first and second group, students had delivered feedback and communicated the idea of product making but the things delivered were not suited to the material or product discussed. The skill which had been achieved by students in this pattern was students had used communication for various purposes such as giving information, instruction, encouragement, and motivation. Besides, students had been able doing communication in environment differ to publication directly by presenting the product in the front of class and publication through media social. The result of presentation from all students was that total of $9.4 \%$ students was included in this pattern.

3.2.2 Pattern II. In pattern II, students mostly had fulfilled two indicators of communication skill. Students who were included in this pattern consist of three groups based on communication skill achieved. The first group was students who had fulfilled all criteria in indicator of skills namely Articulate though and ideas effectively and Use communication for a range of purposes. However, for another two indicators, namely listen effectively and communicate effectively in the diverse environment, students did 
not give feedback which was suited to the topic or product, and the caption writing was not suited also with the material and product through social media.

The second group, an indicator of articulate thought and ideas effectively. Students only able to deliver the idea of product made in written and orally but the idea delivered was not suited to the concept which was being learned whereas in indicator of Use communication for a range of purposes, students only able to use communication for only three purposes. In the second group, two indicators in communication skill which cannot be fulfilled by students were Articulate thought and ideas effectively and the indicator of communicate effectively in diverse environments. The idea of product making design which was delivered was not suited to the concept. Students had been able to do product publication through media social, but the communication used was not effective because the caption given was not suited for the product. Whereas, another two indicators students were able to give feedback suited to the product and material presented then used communication for various purposes. A total of $30.3 \%$ students was included in this pattern.

3.2.3 Pattern II . This pattern obtained the highest percentage compared to another pattern, that was, $40.6 \%$. Students who were included in this pattern were students who only able to achieve one indicator from four indicators of communication skill. There were three groups included in this pattern. In the first group, students were able to fulfill the criteria of listening effectively which indicated that they were able to listen effectively by giving response and feedback which was suited to the topic discussed.

In the second group, students fulfill indicator of Communicate effectively in diverse environments so, in this group students had been able to do communication for public publication in a diverse environment, namely presentation in the classroom and through social media. In the third group, students had been able to fulfill indicator of Use communication for a range of purposes. Students had been communicating effectively for various purposes such as giving information about product making, instruction in individual task assignment in each group, encouragement during preparation and the process of product making and doing communication to motivate their peers.

3.2.4 Pattern $I V$. In this pattern, there was no indicator of communication skill achieved by students. There were two groups in this pattern. In the first group, students were able to deliver the idea, feedback or gave caption in product publication which was suited to the topic discussed. Whereas for the indicator of use communication for a range of purposes, students only able to communicate for only three purposes. The second group, in indicator of articulate though and ideas effectively and indicator of use communication for a range of purposes were included in the low category which indicated that students in this pattern only delivered the idea of product made in written or orally then used two purposes of communication. Whereas for the indicator of listen effectively and communicate effectively in a diverse environments, students did not give feedback and caption of publication which was suited to the theme given by teacher. A total of $18.7 \%$ students was included in this pattern. 


\subsection{Students' Response to The Use of Performance Assessment}

This data comprised students' response to task assignment and feedback given during learning process. The questionnaire result of students' response to the use of performance assessment with four alternatives of the answer provided was as follow:

Table 3.3.1 Data of Students' Response

\begin{tabular}{lll}
\hline \multicolumn{1}{r}{ Response } & \multicolumn{1}{c}{ Task } & \multicolumn{1}{c}{ Feedback } \\
\hline Whole & $31 \%$ & $34 \%$ \\
Most & $47 \%$ & $47 \%$ \\
Few & $18 \%$ & $16 \%$ \\
No & $4 \%$ & $3 \%$ \\
\hline
\end{tabular}

From this data, it could be known that most of the students gave a response to task assignment given by a teacher, which indicated that the question contained in task coul be understood by students. Students more often did communication both directly and indirectly, and the task assignment in the form of the project could help students to understand the material being learned. Similarly, for feedback, most students argued that feedback given by teacher could help them during the task accomplishment, could motivate them to more communicated actively, motivated students to improve their learning style, and the score given by teacher was suited with the ability possessed by students during the learning process.

Based on data of achievement result of communication skill indicators and students' response to the use of performance assessment that using performance assessment could be potentially helped students to posse the skills of the $21^{\text {st }}$ century because the indicator used was the indicator of achievement for $21^{\text {st }}$ century communication skill which was beganing to be developed in education. This is in accord with behaviorism learning theory which explained that the process of behavior change is a result of interaction between stimulus and response process. The stimulus given could invoke behavior response, that was, communication become more active [10]. The behavior theory which was well known as "law of effect" developed by Thorndike stated that if an action invokes positive response was repeated in condition resembled with it, then there is the possibility that that action would be increased [11]. Therefore, if this communication skill was continually trained to students in the different material through performance assessment, then student ability in communicating became more active. The earlier study which had been conducted stated that ideally, communication skill had been inculcated since secondary school because this skill would give the contribution to life-long learning process [12].

\section{Conclusion}

The profile of students' communication skill in each indicator was included in the medium category. Students' response showed that performance assessment helped developing communication skill during learning process. Therefore, communication skill could be more developed again through performance assessment. 


\section{Acknowledgements}

Thanks to SMAN 1 Lembang, Mrs. Noverita, and all participant from first grade to have the contribution in my study. I would like to thank also to my parents for the support they gave to me continually.

\section{References}

[1] Partnership for 21st Century Skills 2015 P21 Framework Definitions (Washington DC: A Partnership for 21 st Century Skills)

[2] Hacicaferoğlu S 2014 International Journal of Science Culture and Sport IntJCCS Survey on the Communication Skills that the College Students of School of Physical Education and Sports Perceived from the Teaching Staff 21

[3] Çetinkaya Z 2011 Kastamonu Education Journal Identifying the opinions of the Turkish prospective teachers regarding the communication skills 192

[4] Chineze, et al. 2016 RedFame Teacher Level Of Awareness of 21st Century Occupational Roles in Rivers State Secondary Schools 491

[5] Jone C A 2005 Assessment for Learning (London:Learning and Skills Development Agency)

[6] Black P, Harrison C, Lee C, Marshall B and William D 2004 Working Inside the Black Box: Assessment for Learning in the Classroom SagepubJournal 91

[7] Oosterhof, A 2003 Developing and Using Classroom Assessment (USA: R.R Donnelley and Company 3rd Edition)

[8] Caspersz D and Stasinska A 2015 Journal of University Teaching \& Learning Practice JUTLP Can we teach effective listening? An exploratory study 124

[9] Morreale S P, Osborn M M and Pearson J C 2000 Journal of the Association for Communication Administration JACA Why Communication is Important: A Rationale for the Centrality of the Study of Communication 292

[10] Suyono and Hariyanto 2011 Belajar dan Pembelajaran (Bandung: PT Remaja Rosdakarya].

[11] Dahar, R W 2011 Teori-Teori Belajar dan Pembelajaran (Jakarta: Penerbit Erlangga)

[12] Riemer, M J 2007 Global J of Engng Educ Communication Skills for the 21st Century Engineer 111 